\title{
Ennio Vivaldi, rector de la Universidad de Chile, sobre la emergencia sanitaria producto de la epidemia de covid-19
}

\section{Claudia Iriarte Rivas (iD}

Universidad de Chile

La emergencia sanitaria producto de la epidemia de covid-19 ha implicado grandes retos y problemas que abordar por parte de la comunidad nacional. En este contexto, la comunidad universitaria no solo ha tenido que dar respuestas a sus propias problemáticas, sino también elaborar planteamientos y propuestas, a partir de su capacidad académica y de conocimiento, para avanzar en la resolución de los desafíos que la pandemia ha significado para nuestra sociedad.

En esta oportunidad conversamos con Ennio Vivaldi, rector de la Universidad de Chile, sobre tópicos centrales de epidemia de covid-19 y el quehacer universitario.

La digitalización de las clases y actividades académicas a causa de la pandemia nos obligó a repensar la forma de hacer universidad. ¿Cuáles cree que son los principales beneficios y desafíos de esta nueva forma de enseñanza? ¿Cómo enfrentarlos?

Lo primero que quisiera señalar es que es distinto el concepto de docencia online, en línea, que significa que uno de antemano se prepara y se programa para hacer un curso con todas las características de un curso en línea y entendiendo las limitaciones y ventajas que eso conlleva, a verse forzado de un día para otro a trasladar la docencia a una docencia en línea. Es conceptualmente distinta la tarea en uno y otro caso, eso es importante tenerlo claro, ya que esto último es lo que ocurrió y creo que a eso respondimos muy bien. La universidad estaba muy bien preparada, teníamos toda una infraestructura de plataforma de computación que con facilidad pudo extender el máximo de cursos al máximo de estudiantes.

Nos planteamos algunos criterios desde la partida. El primero y fundamental es que todos los estudiantes tuvieran acceso a esta modalidad, nosotros no íbamos a 
hacer ninguna actividad que implicara segregar y discriminar a nuestros estudiantes. Es por eso que en los casos en que no tenían mecanismos para conectarse o presentaban serias dificultades, nos preocupamos de dotarlos con los implementos requeridos. Se compraron y entregaron más de 2.000 tablets, se entregaron 2.722 chips, y en otros casos se prestaron equipos. Hubo colaboración externa, hubo empresas que nos donaron medios o chips para los estudiantes. Universia, por ejemplo, nos hizo una donación de chips, y se implementó la campaña «t@dos conectad@s», impulsada por integrantes de la comunidad universitaria, que permitió reunir recursos para la compra de implementos.

La universidad ha logrado implementar el año académico. Hay cifras bastante decidoras de los volúmenes que este desafío implica: hasta la primera semana de junio se han hecho en total 40.769 clases por vía de plataforma; al mes de mayo, 3.349 profesores estaban haciendo clases virtuales. En la plataforma de U-Curso han entrado en mayo 46.299 usuarios.

Yo creo que hay dos cosas que son obvias y todo el mundo las entiende hoy. La primera es que la presencialidad tiene elementos insustituibles. Nadie podría pensar que ahora vamos a poder hacer una universidad no presencial. Eso es absurdo. Pero, por otra parte, también se llega a entender la enorme cantidad de ventajas que tiene la digitalización de la labor académica. Cosas como las métricas se vuelven notablemente más fáciles, precisas y flexibles. Uno puede enterarse de muchos más detalles del proceso de aprendizaje gracias al medio informático.

Es importante también mantener una universidad activa. Ése es un objetivo en sí. Sería muy terrible decir «cada uno para su casa y nos volvemos a ver cuando las condiciones lo permitan». Creo que ahí hay un desafío de mantener una comunidad activa y templada. Desde luego, eso ya genera de por sí lazos entre los estudiantes, inmensas posibilidades de colaboración, etcétera.

Hablando de tecnología informática, quisiera destacar una cosa de la cual nos jactamos poco. El hecho de que Chile sea por lejos el mejor país de América Latina, y tan bueno como países del primer mundo, en cuanto a capacidad de trasladar su docencia universitaria al medio digital. Es gracias, precisamente, a la labor que hicieron en el desarrollo de la informática en el país las universidades en general, y muy en especial la Universidad de Chile y las demás universidades tradicionales. Esto lo enfatizo porque estas cosas no se dicen. Por ejemplo, ahora que se discute el apoyo a distintas universidades, a nadie le gusta reconocer cuánto son ayudadas por lo que ha hecho la universidad tradicional, es una cosa que suele desconocerse. En otras palabras, la capacidad que Chile tiene hoy para responder con un alto nivel de tecnología de la información es gracias, en primerísimo lugar, a la Universidad de Chile y al resto de la comunidad de las universidades, y eso creo que es bueno dejarlo claro. 
Hay mucho debate sobre la transparencia y calidad de la información entregada por las autoridades. ¿Cómo cree usted que la transparencia de los datos entregados por las autoridades puede influir en su credibilidad frente a las medidas que se deban tomar para contener el virus?

Nosotros pensamos que el disponer de datos es clave y que una de las tantas formas que la universidad tiene para colaborar en el manejo de esta crisis es por la vía del análisis de datos. Sin embargo, analizar los datos significa mucho más que objetivarlos en estadísticas. Hoy los datos sirven para hacer modelamientos, y eso es tremendamente importante. El modelamiento es lo que permite anticipar cuál será el impacto de determinadas medidas. Por ejemplo, hoy nuestros equipos en las Facultad de Ciencias Físicas y Matemáticas, junto con profesionales de salud pública, de economía, son capaces de levantar modelos y decir «si hacemos tal cosa, las consecuencias serán éstas, y si hacemos estas otras cosas, las consecuencias serán las siguientes».

Eso es fundamental para que la autoridad pueda tomar decisiones correctas, y es muy importante para que la población entienda realmente qué es lo que hay detrás y cuál es el impacto real de las medidas decretadas por la autoridad. Este aspecto que se reclama es fundamental. Permitiría decirle a la gente: «Si cumplimos estas medidas ocurrirá el escenario uno, y si no cumplimos y hacemos otra cosa va a ocurrir el escenario dos». Estas formas en que la autoridad - a todo nivel, Gobierno central, autoridad local - se vincula o se relaciona con la población son clave para que haya un ejercicio real de participación y de democracia. Por eso es que nosotros insistimos tanto en disponer de los datos.

La pandemia ha puesto de manifiesto diversas desigualdades, en particular respecto de las personas migrantes en situación de irregularidad administrativa. Se han dado casos en que ellas han optado por no asistir a centros de salud, dado su temor a ser identificadas. ¿Cuál cree usted que debe ser el principio orientador para abordar un conflicto como éste?

Yo lo veo desde dos puntos de vista. Señalaría el derecho que tiene toda persona a la salud y que la situación de una permanencia irregular, en la medida en que conspira contra la salud, nos debe hacer reflexionar sobre qué significa mantener a alguien de una manera, digamos, semiclandestina. Que una persona no pueda salir a entregar su identidad o decir quién es, la coloca en un estado muy carenciado en lo que es acceso a servicios esenciales como la salud. Es muy dramático que alguien que tenga una enfermedad grave no reciba asistencia médica por temor a, de ser identificada, tener problemas con la justicia. Ésa es una perspectiva evidente respecto de la cual no cabe decir mucho más. 
La otra perspectiva que también me gustaría enfatizar es cómo esas cosas terminan repercutiendo en el total de la sociedad. Porque yo creo que si algo necesitamos aprender de esta crisis es que debe existir un nivel superior de integración en la sociedad, y que la sociedad no es la suma de todos los individuos ni tampoco la suma de todos los intereses de todos los grupos, sino que se maneja en un nivel de integración distinto. Este es un buen ejemplo, porque si uno parte desde un tema como la migración irregular, termina concluyendo que si esos migrantes no pueden tener las mismas oportunidades para protegerse ellos de la pandemia, como por ejemplo no poder acudir a hacerse el examen, eso no repercute únicamente sobre ellos, sino sobre todos nosotros, porque es un foco que va a mantener, perpetuar y fomentar la pandemia.

Yo he insistido mucho en esto, en el hecho de haber entendido de una manera tan drástica qué significa realmente vivir en sociedad, que somos una sociedad, y creo que los ejemplos han sido evidentes. Si hay sectores de Santiago en los que se vive con hacinamiento, eso no afecta sólo a ese sector, sino que afecta a todo Santiago, porque son lugares donde la pandemia se refuerza. En consecuencia, desde ese punto de vista, creo que los migrantes en situación irregular manifiestan un ejemplo muy marcado de la vulnerabilidad, en primer lugar, para ellos como personas, pero en segundo lugar también para el conjunto del entorno, del contexto y de la sociedad en la cual ellos están.

La universidad, preocupada por este tema, ha trabajado junto a los equipos de salud traduciendo material preventivo del covid-19 al creole, de modo que permita el acceso a información de salud pública a la población haitiana.

En relación con las personas privadas de libertad y el covid-19, a su juicio, ¿qué desafíos plantea la epidemia para garantizar su derecho a la salud?

De las cosas más impresionantes que me ha tocado ver durante estos días, que han sido muchas, fue precisamente la realidad carcelaria del Centro de Detención Penitenciario Santiago Sur (antigua Penitenciaría), el cual nosotros como Universidad de Chile visitamos en conjunto con un grupo de la Universidad Católica, ambos rectores, y el ministro de Justicia. Estuvimos ahí con el jefe de la antigua Penitenciaría, y realmente es una cosa extraordinaria, impresionante. Cuando uno va al panóptico, digamos, escucha los gritos desgarradores de los presos, ve las condiciones objetivas en que están, en verdad es muy terrible. Es una situación que conmociona. Desde luego, uno debería esperar que a partir de la pandemia se avance en una mejora en sus condiciones, por ejemplo, en las condiciones sanitarias. Uno esperaría que hubiera una preocupación por el acceso al agua y todas las cosas mínimas que son fundamentales para la prevención de la enfermedad.

También hay que mencionar que ha habido preocupación. Se han tomado medidas humanitarias tendientes a reducir el hacinamiento en los penales. Por ejemplo, la 
Ley que Concede Indulto General Conmutativo a Causa de la Enfermedad Covid-19 en Chile (Ley 21.228). En ese sentido, hasta donde yo me he informado, no ha habido brotes dentro de las cárceles, al menos en Santiago, lo cual en ningún caso quita el hecho de que debe haber una preocupación por mejorar las condiciones en que ellos viven, sin duda.

Al igual que muchos otros problemas que vivimos hoy, la pandemia del covid-19 constituye un desafío global que requiere también de respuestas globales. ¿Qué rol piensa que deben jugar los derechos humanos en esa discusión? ¿Que esperaría de instituciones internacionales como la Organización Mundial de la Salud o Naciones Unidas?

Desde que esto partió, hemos enfatizado el tema de los derechos humanos. Me parece que todavía tenemos mucho que aprender respecto de esta experiencia, porque se ha visibilizado una cantidad de situaciones en el país que, de algún modo, pasaban inadvertidas o quizás no queríamos ver. De hecho, ya el estallido social es un anuncio de que había un descontento latente y que había condiciones de muy mal vivir en la población chilena de la cual nosotros no tomábamos directamente responsabilidad. Entonces, lo primero es que la pandemia evidencia, por ejemplo, la fragilidad laboral, la precariedad de los puestos de trabajo, hechos que, desde luego, son afectaciones a los derechos humanos.

El hecho mismo de que haya un conflicto entre lo sanitario y lo laboral es impresionante. Es decir, aunque quisiéramos tener cuarentena no podríamos, porque para muchas personas, si no trabajan un día, no comen ese día. O por ejemplo la cantidad de gente que no tiene agua... Entonces, se ha evidenciado durante la pandemia, en términos de las condiciones sanitarias, una serie de situaciones que sin duda riñen con los derechos fundamentales que todo ser humano tiene, o, al menos, las tremendas falencias desde ese punto de vista.

La universidad creo que ha tenido una preocupación especial siempre por el tema de los derechos humanos. Tiene una cátedra de derechos humanos y muchas otras instancias en las cuales impulsamos esto. En la Facultad de Derecho, de Medicina, Arquitectura, entre otras, todos lugares en los cuales nos hemos preocupado de temas que están directamente relacionados con derechos humanos.

Desde el punto de vista internacional, ése es también tremendo aprendizaje. El mundo en la actualidad está tremendamente conectado. La velocidad con la que se expandió esta enfermedad viral es impresionante. Las consecuencias que tiene la interdependencia económica, de producción de materias primas, de producción de objetos manufacturados, etcétera, se manifiestan en un mundo infinitamente más interconectado, y eso se hace evidente. Yo creo que también, entonces, esto es una lección sobre cómo manejar las relaciones internacionales y desde luego queda la evidencia de que hay que actuar de manera coordinada. Esto en Europa se aprendió gracias a la 
Unión Europea, ellos tienen la posibilidad de trabajar en forma mucho más coordinada y de armonizar lo que están haciendo los distintos países. Es fundamental que eso también ocurra en la región latinoamericana. No solamente eso, sino que las organizaciones de salud y las directivas de salud tienen que recoger información, hacer análisis comparativos, hacer estudios, dictaminar órdenes, sugerencias, instructivos, mejores prácticas a todas las comunidades regionales. Entonces, la necesidad de que se establezcan centros de acopio de información, de análisis comparado y que de ahí salgan directivas pasa a ser clave dentro del manejo de la pandemia. Por lo tanto, la razón de ser de organizaciones como Naciones Unidas, la Organización Mundial de la Salud y la Organización Panamericana de la Salud pasa a ser muy importante.

Ciertamente, nosotros tuvimos una ventaja de ver en forma anticipada lo que estaba pasando en Europa y eso nos daba la posibilidad de tomar medidas preparatorias. Pero, sobre todo, yo creo que está el tema de hacer estudios comparados y a partir de ellos tratar de encontrar causas que impliquen las diferentes formas en que se da la pandemia. Se deben analizar las diferentes formas que se propusieron para combatirla, los diferentes modelos que se han planteado, es muy importante que eso vaya a un centro, a un cerebro que recoja toda esa información, la procese, la analice y dé directivas o haga sugerencias con respecto a cuáles son las mejores prácticas. Yo creo que eso en una medida importante se ha logrado. Ahora, es evidente que ha habido órdenes, contraórdenes, lo que en un momento se promovió, después se censuró y viceversa. Eso es parte del proceso, porque es una cosa muy inusual lo que ha ocurrido.

Lo anterior nos lleva a otro tema que tiene que ver con esto, que es cómo uno fija prioridades. Mucho se ha debatido por la prensa o entre diversas personalidades cuáles son las prioridades que hay que considerar para enfrentar las encrucijadas que nos plantea una epidemia como el covid-19. Es muy significativo, en términos de preguntarse si acaso la humanidad misma, en cuanto a la economía global, hasta qué punto es capaz de establecer prioridades. Esto es válido para el mundo y para cada país. Es motivo de reflexión: ¿no deberíamos estar destinando más fondos al estudio para la protección del medio ambiente o la disipación de los virus? Por lo demás, la pandemia es un problema que mucha gente - como también se ha dicho- anticipaba. Entonces no tengo nada contra las estrellas de futbol, pero realmente esa mujer, autoridad de salud española, no deja de tener un argumento importante: ¿cuáles han sido las prioridades de nuestra sociedad? ¿A qué hemos destinado nuestros recursos? ¿Acaso no deberíamos preocuparnos mucho más de mejorar nuestras condiciones en temas como salud, energía, educación y otras cosas? Creo que también es un tema que reclama reflexión, y el cual tiene que ver directamente con la posibilidad de dar una respuesta a la crisis que haga prevalecer los derechos humanos. 


\section{Sobre la autora}

Claudia Iriarte Rivas es abogada. Doctora en Derecho, investigadora del Centro de Derechos Humanos de la Facultad de Derecho. Actualmente se desempeña como editora del Anuario de Derechos Humanos. Su correo electrónico es ciriarter@derecho.uchile.cl. (D) https://orcid.org/00oo-0003-0449-926X. 
El Anuario de Derechos Humanos es una publicación semestral de referencia y consulta en materia de derechos humanos y campos afines. Busca ser un espacio de discusión de los temas centrales en el ámbito nacional e internacional sobre derechos humanos. Es publicado desde 2005 por el Centro de Derechos Humanos de la Facultad de Derecho de la Universidad de Chile.

\author{
EDITORA \\ Claudia Iriarte Rivas \\ ciriarter@derecho.uchile.cl \\ SITIO WEB \\ anuariocdh.uchile.cl \\ CORREO ELECTRÓNICO \\ anuario-cdh@derecho.uchile.cl \\ LICENCIA DE ESTE ARTÍCULO \\ Creative Commons Atribución Compartir Igual 4.o Internacional
}

\author{
\% \\ La edición de textos, el diseño editorial \\ y la conversión a formatos electrónicos de este artículo \\ estuvieron a cargo de Tipográfica \\ (www.tipografica.io)
}

